\title{
Enhanced sensory nerve reactivity in non-eosinophilic asthma
}

\author{
Hajar Ali ${ }^{1}$, Collin Brooks ${ }^{2}$, Julian Crane ${ }^{3}$, Richard Beasley ${ }^{4}$, Stephen Holgate ${ }^{5}$, Peter \\ Gerard Gibson $^{6}$, Philip Pattemore ${ }^{7}$, Yu-Chieh Tzeng ${ }^{8}$, Thorsten Stanley ${ }^{9}$, Neil Pearce ${ }^{10}$, \\ and Jeroen Douwes ${ }^{1}$ \\ ${ }^{1}$ Massey University \\ ${ }^{2}$ Massey University Centre for Public Health Research \\ ${ }^{3}$ Wellington School of Medicine \& Health Sciences \\ ${ }^{4}$ Medical Research Institute of NZ \\ ${ }^{5}$ University of Southampton \\ ${ }^{6}$ The University of Newcastle Hunter Medical Research Institute \\ ${ }^{7}$ Christchurch School of Medicine \\ ${ }^{8}$ University of Otago, Wellington, NZ \\ ${ }^{9}$ University of Otago \\ ${ }^{10}$ London School of Hygiene and Tropical Medicine
}

February 7, 2021

\begin{abstract}
ABSTRACT Background: Neural mechanisms may play an important role in non-eosinophilic asthma. This study compared airway sensory nerve reactivity, using capsaicin challenge, in eosinophilic and non-eosinophilic asthma and non-asthmatics. Methods: Thirty-eight asthmatics and nineteen non-asthmatics (aged 14-21 years) underwent combined hypertonic saline challenge/sputum induction, exhaled nitric oxide (FeNO), atopy, and spirometry tests, followed by capsaicin challenge. Eosinophilic (EA) and non-eosinophilic asthma (NEA) were defined using a sputum eosinophil cut-point of 2.5\%. Airway hyperreactivity (AHR) was defined as a [?]15\% drop in FEV1 during saline challenge. Sensory nerve reactivity was defined as the lowest capsaicin concentration that evoked 5 (C5) coughs. Results: Non-eosinophilic asthmatics (n=20) had heightened capsaicin sensitivity (lower C5) compared to non-asthmatics $(\mathrm{n}=19)$ (geometric mean $\mathrm{C} 5$ : $58.3 \mu \mathrm{M}, 95 \%$ confidence interval $24.1-141.5$ vs $193.6 \mu \mathrm{M}, 82.2-456.0 ; \mathrm{p}<0.05)$. There was a similar (but non-significant) difference in capsaicin sensitivity in NEA compared with EA $(\mathrm{n}=18),(58.3 \mu \mathrm{M}, 24.1-141.5$ vs $191.0 \mu \mathrm{M}, 70.9-514.0 ; \mathrm{p}=0.07)$. FEV1 was significantly reduced from baseline following capsaicin inhalation in both asthmatics and non-asthmatics but no differences were found between subgroups. No associations with capsaicin sensitivity and atopy, sputum eosinophils, blood eosinophils, asthma control, or treatment were observed. Conclusion: Non-eosinophilic asthma, but not eosinophilic asthma, showed enhanced capsaicin sensitivity compared with non-asthmatics. Sensory nerve reactivity may therefore play an important role in the pathophysiology of non-eosinophilic asthma.
\end{abstract}

\section{Hosted file}

Enhanced sensory nerve reactivity in non-eosinophilic asthma.pdf available at https: //authorea.com/users/394205/articles/507638-enhanced-sensory-nerve-reactivity-in-noneosinophilic-asthma 

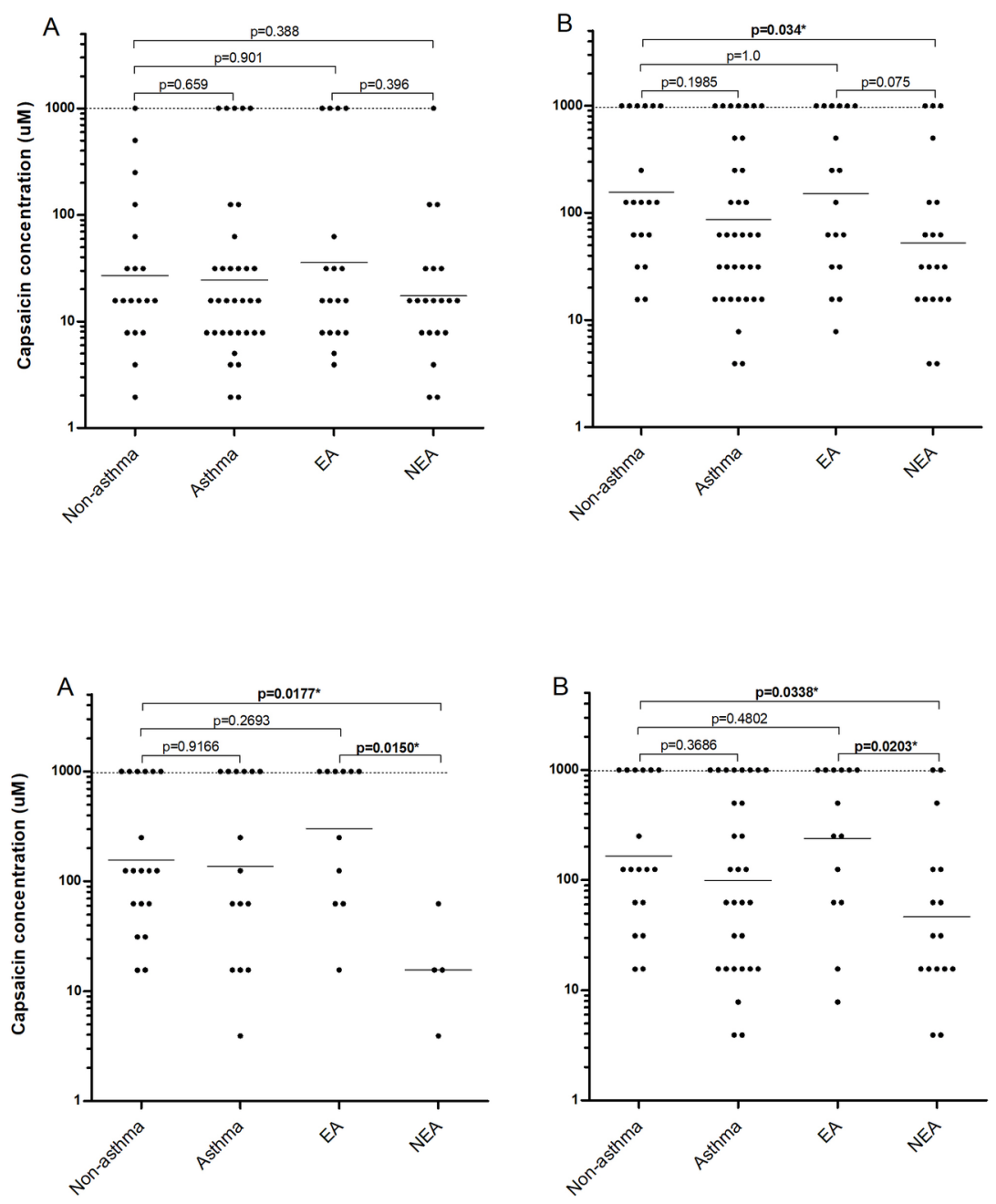